\title{
Breast Carcinoma Metastatic in the Spine
}

National Cancer Institute

\section{Source}

National Cancer Institute. Breast Carcinoma Metastatic in the Spine. NCI Thesaurus.

Code C153226.

A carcinoma that arises from the breast and has spread to the spine. 